Article

\title{
Influence of Co-Catalysts and Polymerization Conditions on Properties of Poly(anhydride-alt-epoxide)s from ROCOP Using Salen Complexes with Different Metals
}

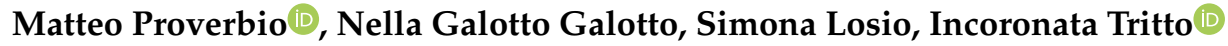 \\ and Laura Boggioni *(D) \\ Institute for Macromolecular Studies, National Research Council, Via A. Corti, 12, 20133 Milan, Italy \\ * Correspondence: boggioni@ismac.cnr.it; Tel.: +39-02-2369-9748; Fax: +39-02-7063-6400
}

Received: 28 June 2019; Accepted: 16 July 2019; Published: 22 July 2019

check for updates

\begin{abstract}
Cyclohexene oxide (CHO) and phthalic anhydride (PA) have been reacted in the presence of commercial salen-type complexes with different metals $\mathrm{Cr}$ (1), $\mathrm{Al}$ (2), and $\mathrm{Mn}$ (3) in combination with 4-(dimethylamino) pyridine (DMAP), bis-(triphenylphosphorydine) ammonium chloride (PPNCl) and bis-(triphenylphosphoranylidene)ammonium azide $\left(\mathrm{PPNN}_{3}\right)$ as co-catalysts to obtain alternating poly(PA-alt-CHO)s by ring-opening copolymerization (ROCOP). The effect of different reaction conditions (pre-contact between catalyst and co-catalyst, polymerization time) on the productivity, molecular weight and glass transition temperature has been evaluated. By using a $24 \mathrm{~h}$ pre-contact, the aliphatic polyesters obtained were characterized by high molecular weight $\left(M_{\mathrm{n}}>15 \mathrm{~kg} / \mathrm{mol}\right)$ and glass transition temperature $\left(T_{\mathrm{g}}\right)$ up to $146^{\circ} \mathrm{C}$; the more sustainable metals $\mathrm{Al}$ and $\mathrm{Mn}$ in the presence of PPNCl give comparable results to $\mathrm{Cr}$. Moreover, biodegradability data of these polyesters and the study of the microstructure reveal that the biodegradability is influenced more by the type of chain linkages rather than by the molecular weight of the polyesters.
\end{abstract}

Keywords: polyesters; ROCOP; high glass transition temperature; high molecular weight

\section{Introduction}

Aliphatic polyesters (PEs) are an appealing class of polymers used in a range of applications such as biomedical devices and bulk packaging owing to their excellent properties and general biocompatibility [1,2]. They are typically synthesized by ring-opening polymerization (ROP) of lactones and lactides [3-5], an excellent controlled polymerization route, which gives polymers with relatively low glass transition temperatures. Alternating ring-opening copolymerization (ROCOP) of epoxides and cyclic anhydrides (Scheme 1) is becoming an attractive method for the synthesis of PEs [6-15]. It represents an alternative chain-growth route to polyesters with respect to the ring-opening polymerization (ROP) of lactones and an opportunity to broaden the range of materials produced and to overcome some of the limitations of ROP. In particular, the properties of the ensuing materials, including the thermal properties (glass transition temperature $\left(T_{\mathrm{g}}\right)$ and thermal decomposition temperature), can be tuned by changing the epoxide or cyclic anhydride. For example, low $T_{\mathrm{g}}$ values can be obtained by monomers with long side chains or using monocyclic epoxides and anhydrides [8,16]. Conversely, high $T_{\mathrm{g}}$ values are favored by rigid backbones, showing the importance of selecting more rigid monomer combinations such as bi- or tricyclic monomers and monomers bearing an aromatic group [9-14,17,18]. 


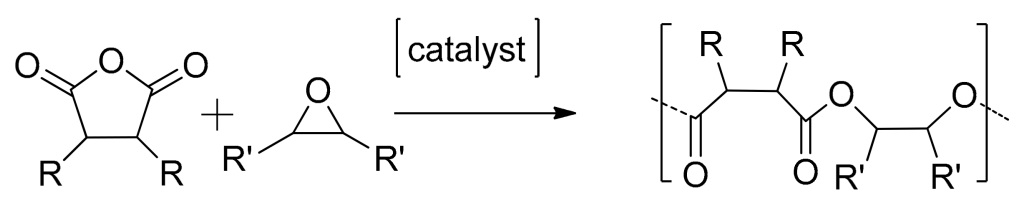

Scheme 1. Ring opening copolymerization (ROCOP).

However, one of the major challenges faced with ROCOP is that the PEs synthesized via this technique are typically of low number average molecular weight $\left(M_{n}\right)$, that renders poor mechanical and thermal properties and thus limits their applications.

In recent years, numerous organometallic catalysts have been developed for epoxide/anhydride copolymerization, including magnesium [11], aluminum [7,12,13,19-22], chromium [8,12,15,21-26], manganese $[12,22,23,27,28]$, iron $[7,29]$, cobalt $[12,15,20-23]$, zinc complexes $[8,9,11]$ and heterodinuclear polymerization catalyst [30-33], many of which showed markedly higher activity with the addition of a nucleophilic co-catalyst [18,29]. Duchateau and coworkers [34] investigated the ROCOP of cyclohexene oxide (CHO) with succinic anhydride (SA), phthalic anhydride (PA), and cyclopropane-1,2-dicarboxylic acid anhydride in bulk and in solution by using different salen or salphen metal complexes such as those of $\mathrm{Al}, \mathrm{Cr}$ and $\mathrm{Co}$, along with several co-catalysts. The most reactive substrate was PA, which yielded a polyester with the highest $M_{\mathrm{n}}$ value by using a combination of salphen $\mathrm{Cr}$ (III) complex catalyst and bis(triphenylphosphine)iminium chloride ( $\mathrm{PPNCl}$ ) as co-catalyst but no information on thermal properties has been reported. Recently, metal-free initiators for the copolymerization of epoxides with anhydrides are being explored [35,36]. A series of dinuclear complexes, in which two iron(III) amino triphenolate moieties are bridged by a phenylene backbone were synthesized by Jiang [37] for the alternating copolymerization of $\mathrm{CHO} / \mathrm{PA}$ in the presence of $\mathrm{PPNCl}$ with good $M_{n}$ value $(33 \mathrm{~kg} / \mathrm{mol})$. However, research efforts in the synthesis of polyesters by ROCOP with high $T_{\mathrm{g}}$ and suitable molecular weight by using commercial catalysts are still necessary.

In this study, an investigation on the influence of co-catalysts and polymerization conditions on alternating ROCOP of $\mathrm{CHO}$ and PA using commercial salen complexes with different metals is reported. The polyesters were characterized by size exclusion chromatography (SEC), differential scanning calorimetry (DSC) and nuclear magnetic resonance (NMR). This research work offers access to PEs with good thermal and molecular weight properties suitable for practical applications. Moreover, the biodegradability data of selected poly(anhydride-alt-epoxide)s are reported.

\section{Materials and Methods}

\subsection{Materials}

Phthalic anhydride (PA), cyclohexene oxide (CHO), 4-(dimethylamino) pyridine (DMAP), bis-(triphenylphosphorydine) ammonium chloride ( $\mathrm{PPNCl}$ ), (R-R)-N,N'-bis (3,5-di-tert-butylsalicylidene)-1,2-cyclohexanediaminochromium(III) chloride, (R-R)-N, $\mathrm{N}^{\prime}$-bis (3,5-di-tert-butylsalicylidene)-1,2-cyclohexanediaminomanganese(III) chloride were purchased from Sigma-Aldrich, Milan, Italy. (R-R)-N,N'-bis (3,5-di-tert-butylsalicylidene)-1,2-cyclohexanediaminoaluminum chloride was purchased from Strem Chemicals (Newburyport, MA, USA). Cyclohexene oxide and dichloromethane $\left(\mathrm{CH}_{2} \mathrm{Cl}_{2}\right)$ were dried over $\mathrm{CaH}_{2}$, distilled and stored on $4 \AA$ molecular sieves under nitrogen. Phthalic anhydride was recrystallized from dichloromethane prior to use. Bis-(triphenylphosphorydine) ammonium chloride was dissolved in dichloromethane and precipitated in diethyl ether $\left(\left(\mathrm{C}_{2} \mathrm{H}_{5}\right)_{2} \mathrm{O}\right)$ twice. 4-(dimethylamino) pyridine was double recrystallized from toluene. The co-catalyst bis-(triphenylphosphorydine) ammonium azide has been synthesized according to literature procedures [24]. All manipulations were performed under an inert atmosphere or in a nitrogen-filled MBraun (M. BRAUN INERTGAS-SYSTEME GMBH (Garching, Germany)) glovebox unless stated otherwise. 


\subsection{Synthesis}

Bulk Polymerization.

In a glove box, a $10 \mathrm{~mL}$ crimp cap vial equipped with a stirring bar was charged with a mixture of catalyst, co-catalyst, epoxide and anhydride with a ratio of 1:1:250:250.

Polymerization in Solvent (No Pre-contact Step).

In a glove box, a $10 \mathrm{~mL}$ crimp cap vial equipped with a stirring bar was charged with a mixture of catalyst, co-catalyst, epoxide, anhydride and $1 \mathrm{~mL}$ of toluene with a ratio of 1:1:250:250.

Polymerization in Solvent with Pre-contact step.

In a glove box, in a $10 \mathrm{~mL}$ crimp cap vial equipped with a stirring bar a mixture of catalyst and co-catalyst was charged in the presence of $1 \mathrm{~mL}$ of toluene and keep stirring for $1 \mathrm{~h}$ or $24 \mathrm{~h}$ (pre-contact step). Then, the epoxide and the anhydride were added. The ratio between catalyst: co-catalyst: epoxide: anhydride was 1:1:250:250.

Then, the vial was placed in an aluminum heating block mounted on top of a stirrer/heating plate. At the end of the polymerization the crude product was precipitated twice in methanol and collected after filtration through a $0.45 \mu \mathrm{m}$ Nylon filter. All the analyses were performed on purified sample. Yield $(\%)$ was calculated as $\frac{\text { yield }(\mathrm{g})}{\mathrm{gCHO}+\mathrm{gPA}} * 100$.

\subsection{Methods}

The copolymers were weighed in a $5 \mathrm{~mm} \mathrm{NMR} \mathrm{tube} \mathrm{and} \mathrm{dissolved} \mathrm{in} \mathrm{CHCl}_{3}$. The spectra were recorded on a Bruker Avance 400 instrument $\left(400 \mathrm{MHz}\left({ }^{1} \mathrm{H}\right) ; 100.58 \mathrm{MHz}\left({ }^{13} \mathrm{C}\right)\right.$; pulse angle $=12.50 \mathrm{~ms}$; acquisition time $=0.94 \mathrm{~s}$; delay $=16 \mathrm{~s})$. The probe head was pre-equilibrated at a fixed temperature of $35^{\circ} \mathrm{C}$.

Differential scanning calorimetry (DSC) analysis was performed on a Perkin Elmer DSC 8000 instrument using cyclic heating and cooling rates of $20^{\circ} \mathrm{C}$ per minute and heated from 20 to $200^{\circ} \mathrm{C}$. The values of glass transition temperature $T_{\mathrm{g}}$ were recorded during the second thermal cycle.

Molar mass analysis was performed using about $12 \mathrm{mg}$ of polymer in THF stabilized with $0.025 \%$ BHT (butylated hydroxytoluene) at $35^{\circ} \mathrm{C}$ by a size exclusion chromatography (SEC) system from Waters W600 (Millford, MA), equipped with a differential refractometer Waters 410 . The column set was Agilent 3 PL GEL (Polypore, Oligopore, $50 \AA$ ).

Biodegradability have been determined by respirometric biochemical oxygen demand (BOD) Oxitop method based on very accurate automatic pressure measurement in a closed bottle. When organic matter biodegrades, it demands a certain amount of oxygen. When oxygen is consumed, pressure falls and at the same time carbon dioxide is produced. The system consists of an OxiTop-C measuring head, an OxiTop Controller OC 100, capable of handling up to 120 warheads, and an inductive stirring system. Screwing in the OxiTop-C measuring head, like a "cover", on the special dark glass bottle, it detects the pressure in the head space, using a small transducer connected to a microprocessor. The bottle was placed on a magnetic stirrer suitable for being introduced into an incubator at the set temperature. The sample volume was chosen based on the presumed BOD (biochemical oxygen demand) value, considering that a too large measuring range will lead to inaccurate results. The OxiTop ${ }^{\circledR}$ respirometric system has a special rubber housing inside where $\mathrm{NaOH}$ tablets that react with $\mathrm{CO}_{2}$ are placed. The removal of $\mathrm{CO}_{2}$ from the gas phase led to a decrease in the pressure of the system that was recorded. By means of suitable calculations, the OxiTop-C measuring heads converted the measurement of the pressure variation directly into $\mathrm{mg} / \mathrm{L}$ of consumed $\mathrm{O}_{2}$.

\section{Results}

To understand the effect of the polymerization conditions to obtain industrially processable alternating poly(anhydride-alt-epoxide)s with $M_{\mathrm{n}}>11,000 \mathrm{~g} / \mathrm{mol}$ and $T_{\mathrm{g}}>80{ }^{\circ} \mathrm{C}$, a series of copolymerizations of $\mathrm{CHO}$ with phthalic anhydride wa performed by the salen-type complexes of three different metals $\mathrm{Cr}$ (1), $\mathrm{Al}$ (2), and $\mathrm{Mn}$ (3) (Scheme 2) in combination with 2-dimethylaminopyridine 
(DMAP), and two onium salts with a bulky cation and two different anions ( $\mathrm{PPNCl}$ and $\mathrm{PPNN}_{3}$ ) as co-catalysts (Scheme 3). Commercially available salen complexes were selected, the chromium complex $\mathbf{1}$ is one of those most studied in ROCOP and in particular was used by Duchateau for the ROCOP of $\mathrm{CHO}$ and anhydrides [34]. The aluminum and manganese catalysts $\mathbf{2}$ and 3, respectively, were selected as possible more sustainable alternatives. The DMAP and PPNCl co-catalysts investigated are also commercially available. In particular, the neutral Lewis base DMAP is one of the most studied and is taken as reference. PPNX are well-known onium salts: $\mathrm{PPNCl}$ is commercially available and in combination with salphen $\mathrm{Cr}$ complex resulted in the most effective in $\mathrm{CHO}$ and $\mathrm{PA}$ copolymerization; $\mathrm{PPNN}_{3}$ is reported as one of the most effective co-catalysts in $\mathrm{CO}_{2}$ and epoxide copolymerization [38].

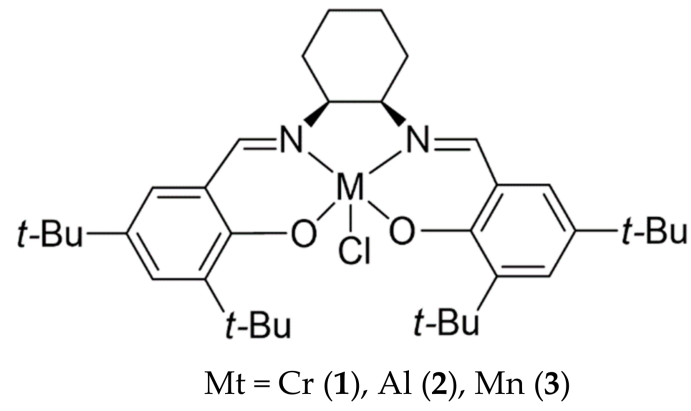

Scheme 2. General structure of (salen) $\mathrm{MtCl}$ catalysts utilized for the copolymerization reactions.<smiles>CN(C)c1ccncc1</smiles>

DMAP

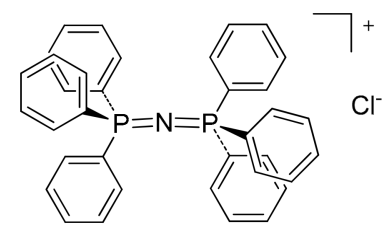

PPNCl

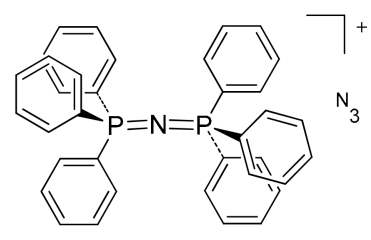

$\mathrm{PPNN}_{3}$

Scheme 3. Structures of co-catalysts utilized for the copolymerization reactions.

\section{ROCOP of CHO Using Complexes 1-3 in Presence of Different Co-Catalysts}

Initially, the copolymerizations of cyclohexene oxide ( $\mathrm{CHO})$ with phthalic anhydride (PA) by (salen) $\mathrm{MtCl}$ catalysts 1, 2 and 3 and DMAP and $\mathrm{PPNCl}$ as co-catalysts were performed at $110{ }^{\circ} \mathrm{C}$ in bulk without pre-contact step between catalyst and co-catalyst, in polymerization conditions reported in the literature [34]. The results are shown in Table 1.

Table 1. Cyclohexene oxide (CHO)/phthalic anhydride (PA) bulk copolymerization ${ }^{a}$.

\begin{tabular}{|c|c|c|c|c|c|c|c|c|c|}
\hline \multirow{2}{*}{ Entry } & \multirow{2}{*}{$\begin{array}{c}\text { Catalyst/ } \\
\text { Co-Catalyst }\end{array}$} & \multirow{2}{*}{$\begin{array}{l}\text { Time } \\
\text { (h) }\end{array}$} & \multirow{2}{*}{$\begin{array}{c}\text { Yield } \\
(\%)\end{array}$} & \multicolumn{2}{|c|}{ Conversion $(\%)^{b}$} & \multirow{2}{*}{$\begin{array}{c}\text { Ether } \\
\text { Linkages } \\
(\mathrm{mol} \%) \text { b }\end{array}$} & \multirow{2}{*}{$\begin{array}{c}M_{\mathrm{n}} \\
(\mathrm{kg} / \mathrm{mol})\end{array}$} & \multirow{2}{*}{$\bigoplus$} & \multirow{2}{*}{$T_{\mathrm{g}}\left({ }^{\circ} \mathrm{C}\right)$} \\
\hline & & & & $\mathrm{CHO}$ & PA & & & & \\
\hline CHOPA 66 & 1/DMAP & 0.3 & 74 & 92 & 63 & 27 & 1.7 & 3.2 & 141 \\
\hline CHOPA 69 & 1/PPNCl & 0.3 & 82 & 87 & 78 & 16 & 1.8 & 3.0 & 141 \\
\hline CHOPA 68 & 2/DMAP & 1.1 & 71 & 78 & 66 & 18 & 2.3 & 2.5 & 136 \\
\hline CHOPA 71 & 2/PPNCl & 1.1 & 57 & 64 & 53 & 20 & 1.9 & 2.9 & 137 \\
\hline CHOPA 67 & 3/DMAP & 1.0 & 76 & 84 & 71 & 15 & 2.4 & 2.5 & 139 \\
\hline CHOPA 70 & $3 / \mathrm{PPNCl}$ & 1.0 & 81 & 86 & 78 & 16 & 2.5 & 2.0 & 139 \\
\hline
\end{tabular}

a Polymerization conditions: temperature $=110^{\circ} \mathrm{C}, \mathrm{CHO}:$ PA:cat:cocat $=250: 250: 1: 1$, catalyst $(20 \mu \mathrm{mol})$ and co-catalyst $(20 \mu \mathrm{mol})$, oxirane $(5 \mathrm{mmol})$ and anhydride $(5 \mathrm{mmol}) .{ }^{\mathrm{b}}$ Calculated from ${ }^{1} \mathrm{H}$ NMR spectra of purified samples.

In our hands, the viscosity of the system increased rapidly especially with catalyst $\mathbf{1}$ and therefore the reactions were stopped after a short time. Yields were high, catalyst $\mathbf{1}$ resulted to be the most active one, and in general, $\mathrm{PPNCl}$ resulted to be the best co-catalyst. The resulting polyesters were characterized by ${ }^{1} \mathrm{H}$ NMR, SEC and DSC. A relatively high amount of ether linkages (see ${ }^{1} \mathrm{H}$ NMR 
results below) was observed under these conditions. The measured numbers average molecular weight $M_{\mathrm{n}}$ ranged from 1700 to $2500 \mathrm{~g} / \mathrm{mol}$. Interestingly, even though molar mases were low probably due to the short polymerization time and high viscosity, the $T_{\mathrm{g}}$ values were higher than $135^{\circ} \mathrm{C}$, and for copolymers by catalyst $1 T_{\mathrm{g}}$ values of $141^{\circ} \mathrm{C}$ were recorded.

Successively, with the purpose to increase the molecular weights, a series of copolymerization of $\mathrm{CHO}$ and PA were performed in solution by adding $1 \mathrm{~mL}$ of toluene in order to reduce the viscosity of the reaction medium. The copolymerizations were carried out in the presence of catalyst $\mathbf{1}$ and DMAP and as expected, the presence of a small amount of solvent decreases the viscosity of the reaction medium, and the molecular weight of CHO/PA copolymers increases up to $9500 \mathrm{~g} / \mathrm{mol}$.

Then, to make homogeneous comparisons in all copolymerizations a pre-contact step between catalysts and co-catalysts was introduced since PPNX salts are insoluble or very sparingly soluble in epoxides at room temperature. Darensbourg [39] reported that for the copolymerization of $\mathrm{CHO}$ and $\mathrm{CO}_{2}$ a pre-contact step seems to be a key factor in the copolymerization reaction. The catalysts and the different co-catalysts were dissolved in toluene and stirred for $1 \mathrm{~h}$ at room temperature (pre-contact step), upon removing the solvent under vacuum, cyclohexene oxide was added with stirring. In Tables 2-4 the results of the copolymerizations performed with catalysts 1, 2 and 3, respectively, with different co-catalysts at different reaction times, are listed.

The comparison of entries in Table 2 shows in a glance that the pre-contact step was crucial: high values of $M_{n}$ for the copolymers prepared in solution and in the presence of the pre-contact step as well as increase in the $T_{\mathrm{g}}$ values were obtained. In general, good yields were obtained with the three different co-catalysts although the catalytic system 1/PPNCl gave higher productivity, especially at short polymerization time. A prolonged reaction time $(24 \mathrm{~h})$ does not seem to further affect the performance of catalyst 1 with the three co-catalysts.

Table 2. CHO/PA copolymerization catalyzed by complex $\mathbf{1}$ and different co-catalysts ${ }^{\text {a }}$.

\begin{tabular}{ccccccc}
\hline Entry & Co-Catalyst & Time (h) & Yield (\%) & $\boldsymbol{M}_{\mathbf{n}}(\mathbf{k g} / \mathbf{m o l})$ & $\boldsymbol{\oplus}$ & $\boldsymbol{T}_{\mathbf{g}}\left({ }^{\circ} \mathbf{C}\right)$ \\
\hline CHOPA 48 & DMAP & 1 & 76 & 15.5 & 1.2 & 147 \\
CHOPA 19 & DMAP & 3 & 91 & 17.5 & 1.2 & 146 \\
CHOPA 20 & DMAP & 24 & 82 & 15.4 & 1.3 & 146 \\
\hline CHOPA 51 & PPNCl & 1 & 90 & 15.7 & 1.1 & 146 \\
CHOPA 17 & PPNCl & 3 & 90 & 16.1 & 1.2 & 145 \\
CHOPA 18 & PPNCl & 24 & 92 & 16.8 & 1.3 & 145 \\
\hline CHOPA 54 & PPNN $_{3}$ & 1 & 84 & 14.8 & 1.1 & 146 \\
CHOPA 36 & PPNN $_{3}$ & 3 & 88 & 14.2 & 1.1 & 147 \\
CHOPA 37 & PPNN $_{3}$ & 24 & 79 & 15.2 & 1.1 & 146 \\
\hline
\end{tabular}

a Polymerization in solution and with $1 \mathrm{~h}$ pre-contact step: solvent $=$ toluene $=1 \mathrm{~mL}$, temperature $=110^{\circ} \mathrm{C}$, CHO:PA:cat:cocat $=$ 250:250:1:1.

Table 3. CHO/PA copolymerization catalyzed by complex 2 and different co-catalysts ${ }^{\text {a }}$.

\begin{tabular}{ccccccc}
\hline Entry & Co-Catalyst & Time (h) & Yield (\%) & $\boldsymbol{M}_{\mathbf{n}} \mathbf{( \mathbf { k g } / \mathbf { m o l } )}$ & $\mathbf{D}$ & $\boldsymbol{T}_{\mathbf{g}}\left({ }^{\circ} \mathbf{C}\right)$ \\
\hline CHOPA 50 & DMAP & 1 & 16 & 4.5 & 1.36 & 129 \\
CHOPA 23 & DMAP & 3 & 66 & 10.4 & 1.47 & 136 \\
CHOPA 24 & DMAP & 24 & 85 & 14.1 & 1.24 & 143 \\
\hline CHOPA 53 & PPNCl & 1 & 40 & 9.4 & 1.10 & 133 \\
CHOPA 21 & PPNCl & 3 & 84 & 16.0 & 1.16 & 144 \\
CHOPA 22 & PPNCl & 24 & 95 & 15.8 & 1.25 & 145 \\
\hline CHOPA 56 & PPNN $_{3}$ & 1 & 41 & 8.8 & 1.10 & 140 \\
CHOPA 38 & PPNN $_{3}$ & 3 & 76 & 12.8 & 1.17 & 144 \\
CHOPA 39 & PPNN $_{3}$ & 24 & 78 & 9.3 & 1.24 & 144 \\
\hline
\end{tabular}

a Polymerization in solution and with $1 \mathrm{~h}$ pre-contact step: solvent $=$ toluene $=1 \mathrm{~mL}$, temperature $=110^{\circ} \mathrm{C}$, CHO:PA:cat:cocat $=$ 250:250:1:1. 
Table 4. CHO/PA copolymerization catalyzed by complex 3 and different co-catalysts ${ }^{a}$.

\begin{tabular}{ccccccc}
\hline Entry & Co-Catalyst & Time (h) & Yield (\%) & $\boldsymbol{M}_{\mathbf{n}} \mathbf{( \mathbf { k g } / \mathbf { m o l } )}$ & $\boldsymbol{\Xi}$ & $\boldsymbol{T}_{\mathbf{g}}\left({ }^{\circ} \mathbf{C}\right)$ \\
\hline CHOPA 49 & DMAP & 1 & 14 & 4.5 & 1.31 & 144 \\
CHOPA 27 & DMAP & 3 & 74 & 12.0 & 1.17 & $/$ \\
CHOPA 28 & DMAP & 24 & 96 & 14.0 & 1.27 & $/$ \\
\hline CHOPA 52 & PPNCl & 1 & 35 & 7.8 & 1.21 & 137 \\
CHOPA 25 & PPNCl & 3 & 86 & 14.9 & 1.15 & 144 \\
CHOPA 26 & PPNCl & 24 & 92 & 15.1 & 1.26 & 144 \\
\hline CHOPA 55 & PPNN $_{3}$ & 1 & 39 & 7.5 & 1.19 & 136 \\
CHOPA 40 & PPNN $_{3}$ & 3 & 68 & 12.6 & 1.20 & 138 \\
CHOPA 41 & PPNN $_{3}$ & 24 & 81 & 15.7 & 1.22 & 144 \\
\hline
\end{tabular}

a Polymerization in solution and with $1 \mathrm{~h}$ pre-contact step: solvent $=$ toluene $=1 \mathrm{~mL}$, temperature $=110{ }^{\circ} \mathrm{C}$ CHO:PA:cat:cocat $=$ 250:250:1:1.

Regarding the aluminum-based catalyst 2 (Table 3) and the manganese-based catalyst 3 (Table 4), they seemed less promising than the chromium one in terms of productivity at short polymerization time. Conversely, a prolonged polymerization time positively affected the productivity as well the molecular weight and $T_{\mathrm{g}} \mathrm{s}$. Molar masses, yields and $T_{\mathrm{g}}$ compared well with those obtained with the chromium based complex 1 . PPNCl proved to be the best co-catalyst for the three catalytic precursors.

In addition, we investigated the effect of the pre-contact time on the $\mathrm{CHO} / \mathrm{PA}$ copolymerizations. A series of additional experiments using a pre-contact time of $24 \mathrm{~h}$ and a polymerization time of $1 \mathrm{~h}$ was also conducted. The obtained results are compared in Table 5.

Table 5. CHO/PA copolymerization with different pre-contact times ${ }^{\text {a }}$.

\begin{tabular}{cccccccc}
\hline Entry & $\begin{array}{c}\text { Catalyst/ } \\
\text { Co-Catalyst }\end{array}$ & $\begin{array}{c}\text { Polym. } \\
\text { Time (h) }\end{array}$ & $\begin{array}{c}\text { Pre-Contact } \\
\text { Time (h) }\end{array}$ & Yield (\%) & $\begin{array}{c}\boldsymbol{M}_{\mathbf{n}} \\
\mathbf{( k g} / \mathbf{m o l})\end{array}$ & $\boldsymbol{\Xi}$ & $\begin{array}{c}\boldsymbol{T}_{\mathbf{g}} \\
\left({ }^{\circ} \mathbf{C}\right)\end{array}$ \\
\hline CHOPA 48 & 1/DMAP & 1 & 1 & 76 & 15.5 & 1.20 & 147 \\
CHOPA 57 & 1/DMAP & 1 & 24 & 64 & 16.3 & 1.20 & 147 \\
CHOPA 20 & 1/DMAP & 24 & 1 & 82 & 15.4 & 1.30 & 146 \\
CHOPA 51 & 1/PPNCl & 1 & 1 & 90 & 15.7 & 1.10 & 146 \\
CHOPA 60 & 1/PPNCl & 1 & 24 & 90 & 15.7 & 1.13 & 146 \\
CHOPA 18 & 1/PPNCl & 24 & 1 & 92 & 16.8 & 1.30 & 145 \\
CHOPA 54 & 1/PPNN & 1 & 1 & 84 & 14.8 & 1.10 & 146 \\
CHOPA 63 & 1/PPNN & 1 & 24 & 89 & 15.5 & 1.10 & 143 \\
CHOPA 37 & 1/PPNN & 24 & 1 & 79 & 15.2 & 1.10 & 146 \\
\hline CHOPA 50 & 2/DMAP & 1 & 1 & 16 & 4.5 & 1.36 & 129 \\
CHOPA 59 & 2/DMAP & 1 & 24 & 80 & 14.2 & 1.13 & 145 \\
CHOPA 24 & 2/DMAP & 24 & 1 & 85 & 14.1 & 1.24 & 143 \\
CHOPA 53 & 2/PPNCl & 1 & 1 & 40 & 9.4 & 1.10 & 133 \\
CHOPA 62 & 2/PPNCl & 1 & 24 & 92 & 16.3 & 1.11 & 146 \\
CHOPA 22 & 2/PPNCl & 24 & 1 & 95 & 15.8 & 1.25 & 145 \\
CHOPA 56 & 2/PPNN & 1 & 1 & 41 & 8.8 & 1.10 & 140 \\
CHOPA 65 & 2/PPNN & 1 & 24 & 93 & 16.2 & 1.20 & 148 \\
CHOPA 39 & 2/PPNN & 24 & 1 & 78 & 9.3 & 1.24 & 144 \\
\hline CHOPA 49 & 3/DMAP & 1 & 1 & 14 & 4.5 & 1.31 & 144 \\
CHOPA 58 & 3/DMAP & 1 & 24 & 84 & 15.4 & 1.13 & 147 \\
CHOPA 28 & 3/DMAP & 24 & 1 & 96 & 14.0 & 1.27 & 144 \\
CHOPA 52 & 3/PPNCl & 1 & 1 & 35 & 7.8 & 1.21 & 137 \\
CHOPA 61 & 3/PPNCl & 1 & 24 & 98 & 14.8 & 1.09 & 146 \\
CHOPA 26 & 3/PPNCl & 24 & 1 & 92 & 15.1 & 1.26 & 144 \\
CHOPA 55 & 3/PPNN & 1 & 1 & 39 & 7.5 & 1.19 & 136 \\
CHOPA 64 & 3/PPNN & 1 & 24 & 97 & 14.7 & 1.20 & 145 \\
CHOPA 41 & 3/PPNN & 24 & 1 & 81 & 15.7 & 1.22 & 144 \\
\hline
\end{tabular}

a Polymerization conditions: solvent $=$ toluene $=1 \mathrm{~mL}$, temperature $=110^{\circ} \mathrm{C}, \mathrm{CHO}:$ PA:cat:cocat $=250: 250: 1: 1$. 
For catalyst 1 there was no great performance difference by varying the pre-contact time from 1 to $24 \mathrm{~h}$ for the same reaction time $(1 \mathrm{~h})$, or using a long pre-contact time $(24 \mathrm{~h})$ or a long polymerization time ( $24 \mathrm{~h}$, see entries 63 vs. 37) for the three different co-catalysts. By using the catalysts 2 and 3 , appreciable differences in the performances have been obtained by varying the pre-contact time from 1 to $24 \mathrm{~h}$ for the same reaction time $(1 \mathrm{~h})$, while small differences are found by exchanging 1 to $24 \mathrm{~h}$ of pre-contact with 24 and $1 \mathrm{~h}$ of polymerization time differences. It is worth noting that with $24 \mathrm{~h}$ of pre-contact and $1 \mathrm{~h}$ of polymerization catalysts 2 and 3 , in terms of activity, molecular weight and thermal properties, compared very well with performances of catalyst 1 . Since this effect was evident also with DMAP as co-catalyst, this indicated that the pre-contact time was important not only because of the solubility of the two phosphonium salts, but also because it facilitated the formation of the active species. This result is important since at higher polymerization time side reactions can occur $[19,40,41]$. Thus, copolymer microstructure has been investigated by ${ }^{1} \mathrm{H}$ NMR.

Indeed, the samples prepared at different pre-contact and polymerization times showed some differences in the microstructure. The ${ }^{1} \mathrm{H}$ NMR spectra of the polyesters synthesized with a pre-contact of $1 \mathrm{~h}$ and $24 \mathrm{~h}$ of polymerization always presented a broad peak between 3.6 and $3.2 \mathrm{ppm}$ corresponding to $\mathrm{CHO}-\mathrm{CHO}$ ether linkage, as displayed in Figure 1. It seems that the homopolymerization of epoxides could occur as a side reaction when the polymerization is complete $[19,40,41]$.
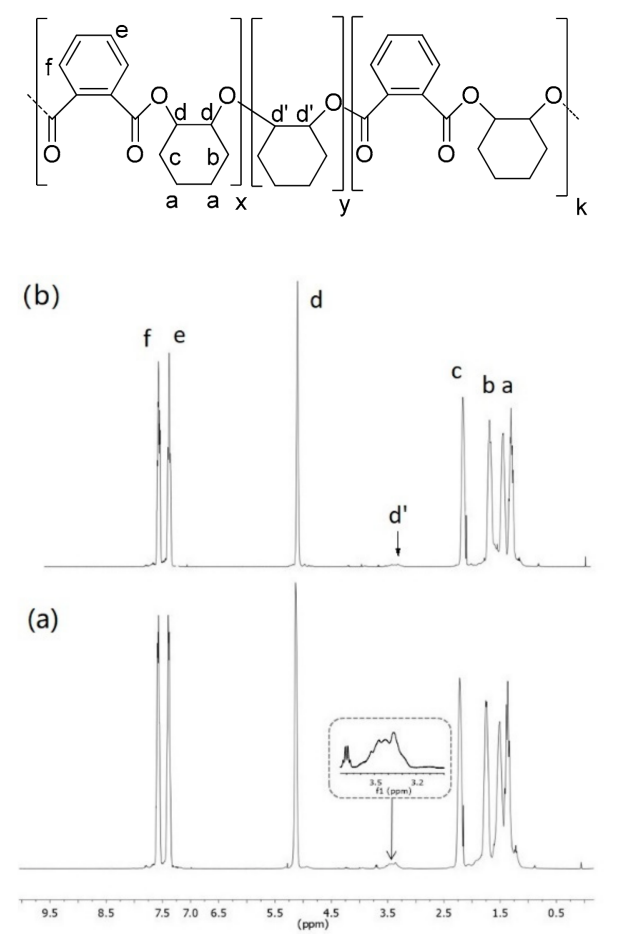

Figure 1. ${ }^{1} \mathrm{H}$ NMR spectra of poly(CHO-alt-PA) obtained with catalyst $\mathbf{1}$ and $\mathrm{PPNCl}$ as co-catalyst with a pre-contact of $1 \mathrm{~h}$ and polymerization time of: (a) $24 \mathrm{~h}$ (entry CHOPA 18) and (b) $1 \mathrm{~h}$ (entry CHOPA 51).

This general behavior is well visible in Figure 2, where the $\mathrm{CHO}$ ether linkage percentage for the different catalytic systems with a pre-contact of $1 \mathrm{~h}$ and different polymerization time is reported. From this point of view, at short polymerization time $\mathrm{PPNCl}$ gave the best results with $\mathrm{Al}$ and $\mathrm{Cr}$ catalysts.

Since biodegradability is one of the interesting properties of these polymers, biodegradability tests were performed according to ISO standards 14,851 (Determination of the ultimate aerobic biodegradability of plastic materials in an aqueous medium) on three polyesters CHOPA 19, CHOPA 60 and CHOPA 66 obtained with catalyst 1 at different polymerization conditions by using the respirometric BOD (biochemical oxygen demand) Oxitop method. CHOPA 19 and CHOPA 60 were 
obtained in polymerization solution at different pre-contact ( $1 \mathrm{vs} .24 \mathrm{~h})$ and polymerization times ( 3 vs. $1 \mathrm{~h}$ ), showing very similar molecular weight $M_{\mathrm{n}}(17.5 \mathrm{~kg} / \mathrm{mol}$ for CHOPA 19 and $15.7 \mathrm{~kg} / \mathrm{mol}$ for CHOPA 60 ) and ether linkage $<7 \%$. CHOPA 66 was obtained in bulk and showed a very low molecular weight $\left(M_{n}=1.6 \mathrm{~kg} / \mathrm{mol}\right)$ with an ether linkage $>27 \%$. Figure 3 shows the biodegradation curves (average values) as a function of time for the three CHOPA samples and for the microcrystalline cellulose used as reference material. In the curves we can distinguish a lag phase, the biodegradation phase and the plateau. For all three samples the biodegradation phase started after 30 days, that of cellulose after 8 days. The curves of CHOPA 19 and CHOPA 60 were almost overlapping, with a plateau phase close to $32 \%$, well above that of CHOPA 66 which did not reach $12 \%$ (Figure 3).

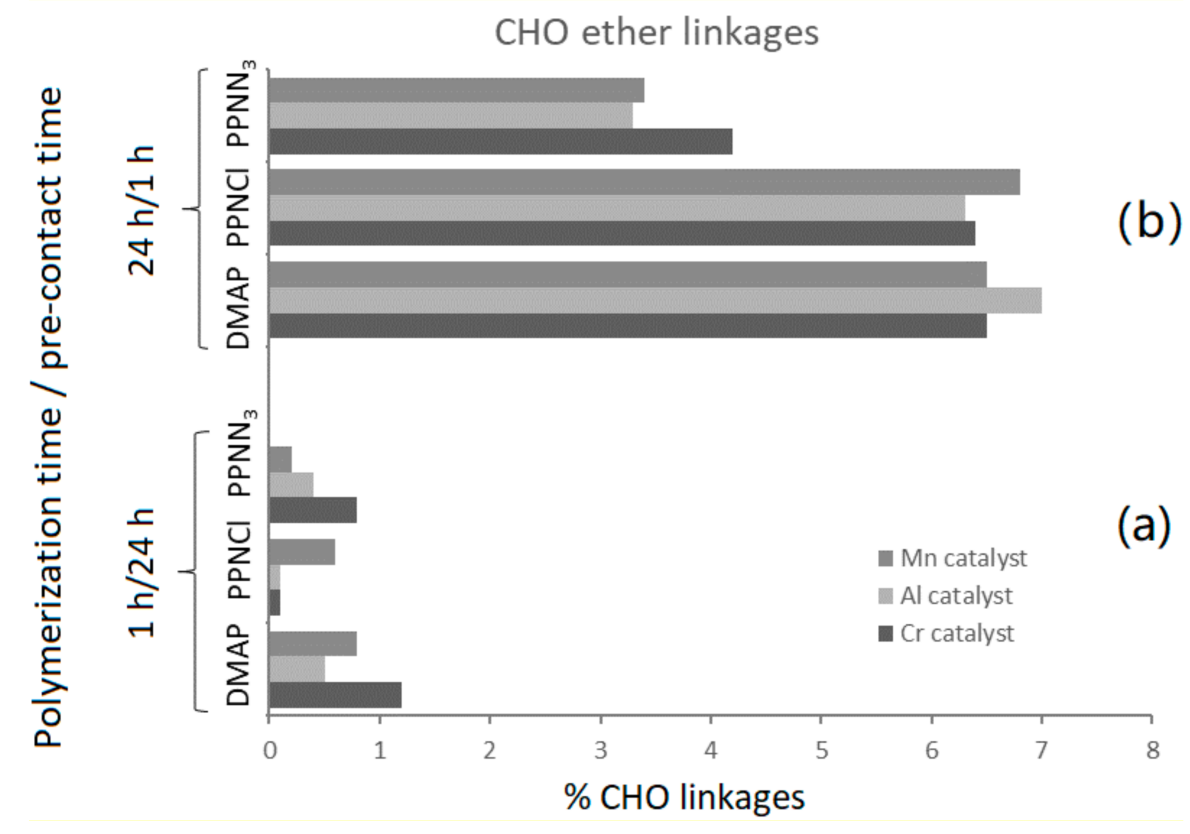

Figure 2. $\mathrm{CHO}-\mathrm{CHO}$ ether linkage percentage for the different catalytic systems with a polymerization time/pre-contact time of $1 \mathrm{~h} / 24 \mathrm{~h} \mathrm{(a)}$ and of $24 \mathrm{~h} / 1 \mathrm{~h} \mathrm{(b)}$.

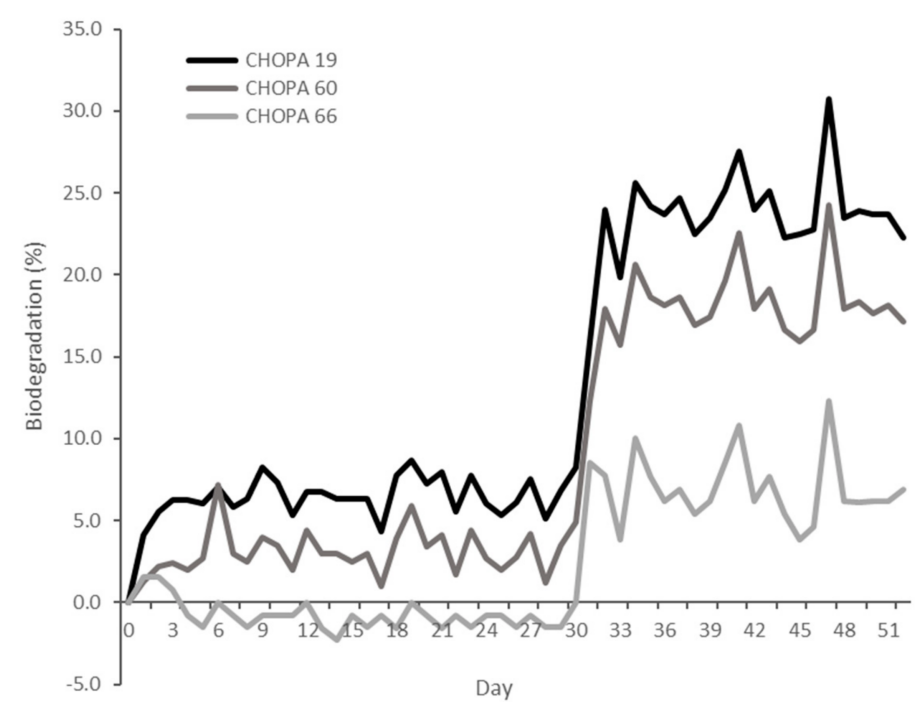

Figure 3. Biodegradation curves for $\mathrm{CHO} / \mathrm{PA}$ polyesters.

From these data one can deduce that biodegradability was influenced more by the type of chain linkage rather than by the molecular weight of the polyesters. Therefore, the methodology used 
for polymerization, which influenced polymer microstructure was key in obtaining biodegradable poly(anhydride-alt-epoxide)s.

\section{Conclusions}

In conclusion, we examined the influence of different polymerization conditions on the copolymerization of cyclohexene oxide with phthalic anhydride by commercial salen complexes 1-3 in combination with DMAP, $\mathrm{PPNCl}$ and $\mathrm{PPNN}_{3}$. The pre-contact step between catalyst and co-catalyst is a key factor in obtaining polymers with molecular weight $>15 \mathrm{~kg} / \mathrm{mol}$ and glass transition temperature up to $140{ }^{\circ} \mathrm{C}$ in high yields. In general, prolonged polymerization times lead to the formation of large quantities of $\mathrm{CHO}-\mathrm{CHO}$ ether linkage, which lowers the poly(CHO-alt-PA)s biodegradability.

Finally, since with a long pre-contact time, but at short polymerization time, the catalysts $\mathbf{2}$ and 3 with more sustainable $\mathrm{Al}$ and $\mathrm{Mn}$ metals in the presence of $\mathrm{PPNCl}$ give comparable results to those from the benchmark Cr catalyst, $\mathbf{2}$ and $\mathbf{3}$ may be a more sustainable alternative.

Author Contributions: Conceptualization, L.B.; methodology, L.B.; polymer synthesis, M.P., N.G.G., microstructural and chain end analysis, S.L., writing and review, L.B. and I.T.

Funding: This research was funded by CARIPLO FOUNDATION, grant number 2016-0643.

Acknowledgments: The authors thank Paola Rizzarelli (IPCB-CNR) and Marco Rapisarda (IPCB-CNR) for the biodegradability test.

Conflicts of Interest: The authors declare no conflict of interest.

\section{References}

1. Rabnawaz, M.; Wyman, I.; Auras, R.; Cheng, S. A roadmap towards green packaging: The current status and future outlook for polyesters in the packaging industry. Green Chem. 2017, 19, 4737-4753. [CrossRef]

2. Hillmyer, M.A.; Tolman, W.B. Aliphatic Polyester Block Polymers: Renewable, Degradable, and Sustainable. Accounts Chem. Res. 2014, 47, 2390-2396. [CrossRef] [PubMed]

3. Ajellal, N.; Carpentier, J.F.; Guillaume, C.; Guillaume, S.M.; Helou, M.; Poirier, V.; Sarazin, Y.; Trifonov, A. Metal-catalyzed immortal ring-opening polymerization of lactones, lactides and cyclic carbonates. Dalton Trans. 2010, 39, 8363-8376. [CrossRef] [PubMed]

4. Mecerreyes, D.; Jerome, R.; Dubois, P. Novel Macromolecular Architectures Based on Aliphatic Polyesters: Relevance of the "Coordination-Insertion" Ring-Opening Polymerization. In Macromolecular Architectures. Advances in Polymer Science; Springer: Berlin/Heidelberg, Germany, 1999; Volume 147, pp. 1-59.

5. Dijkstra, P.J.; Du, H.; Feijen, J. Single site catalysts for stereoselective ring-opening polymerization of lactides. Polym. Chem. 2011, 2, 520-527. [CrossRef]

6. Longo, J.M.; Sanford, M.J.; Coates, G.W. Ring-Opening Copolymerization of Epoxides and Cyclic Anhydrides with Discrete Metal Complexes: Structure-Property Relationships. Chem. Rev. 2016, 116, 15167-15197. [CrossRef] [PubMed]

7. Sanford, M.J.; Carrodeguas, L.P.; Van Zee, N.J.; Kleij, A.W.; Coates, G.W. Alternating Copolymerization of Propylene Oxide and Cyclohexene Oxide with Tricyclic Anhydrides: Access to Partially Renewable Aliphatic Polyesters with High Glass Transition Temperatures. Macromolecules 2016, 49, 6394-6400. [CrossRef]

8. DiCiccio, A.M.; Coates, G.W. Ring-Opening Copolymerization of Maleic Anhydride with Epoxides: A Chain-Growth Approach to Unsaturated Polyesters. J. Am. Chem. Soc. 2011, 133, 10724-10727. [CrossRef]

9. Jeske, R.C.; DiCiccio, A.M.; Coates, G.W. Alternating Copolymerization of Epoxides and Cyclic Anhydrides: An Improved Route to Aliphatic Polyesters. J. Am. Chem. Soc. 2007, 129, 11330-11331. [CrossRef]

10. Harrold, N.D.; Li, Y.; Chisholm, M.H. Studies of Ring-Opening Reactions of Styrene Oxide by Chromium Tetraphenylporphyrin Initiators. Mechanistic and Stereochemical Considerations. Macromolecules 2013, 46, 692-698. [CrossRef]

11. Saini, P.K.; Romain, C.; Zhu, Y.; Williams, C.K. Di-magnesium and zinc catalysts for the copolymerization of phthalic anhydride and cyclohexene oxide. Polym. Chem. 2014, 5, 6068-6075. [CrossRef]

12. Paoniasari, A.; Duchateau, R.; Nejad, E.H.; Koning, C.E. Semi-aromatic polyesters by alternating ring-opening copolymerisation of styrene oxide and anhydrides. Polym. Chem. 2012, 3, 1308-1313. 
13. Aida, T.; Inoue, S. Catalytic Reaction on Both Sides of a Metalloporphyrin Plane Alternating Copolymerization of Phthalic Anhydride and Epoxypropane with an Aluminum Porphyrin-Quaternary Salt System. J. Am. Chem. Soc. 1985, 107, 1358-1364. [CrossRef]

14. Si, G.; Li, B.; Dong, J.; Zhang, L.; Han, B.; Duan, Z.; Liu, B. Novel chromium complexes with a [OSSO]-type bis(phenolato) dianionic ligand mediate the alternating ring-opening copolymerization of epoxides and phthalic anhydride. Polym. Chem. 2015, 6, 6372-6377. [CrossRef]

15. Winkler, M.; Romain, C.; Meier, M.A.R.; Williams, C.K. Renewable polycarbonates and polyesters from 1,4-cyclohexadiene. Green Chem. 2015, 17, 300-306. [CrossRef]

16. Biermann, U.; Sehlinger, A.; Meier, M.A.R.; Metzger, J.O. Catalytic Copolymerization of Methyl 9,10-Epoxystearate and Cyclic Anhydrides under Neat Conditions. Eur. J. Lipid Sci. Technol. 2016, 118, 104-110. [CrossRef]

17. Carrodeguas, L.P.; Martín, C.; Kleij, A.W. Semiaromatic Polyesters Derived from Renewable Terpene Oxides with High Glass Transitions. Macromolecules 2017, 50, 5337-5345. [CrossRef]

18. Han, B.; Zhang, L.; Liu, B.; Dong, X.; Kim, I.; Duan, Z.; Theato, P. Controllable Synthesis of Stereoregular Polyesters by Organocatalytic Alternating Copolymerizations of Cyclohexene Oxide and Norbornene Anhydrides. Macromolecules 2015, 48, 3431-3437. [CrossRef]

19. Van Zee, N.J.; Sanford, M.J.; Coates, G.W. Electronic Effects of Aluminum Complexes in the Copolymerization of Propylene Oxide with Tricyclic Anhydrides: Access to Well-Defined, Functionalizable Aliphatic Polyesters. J. Am. Chem. Soc. 2016, 138, 2755-2761. [CrossRef]

20. Ren, W.-M.; Lu, X.-B.; Li, J.; Liu, Y. Asymmetric Alternating Copolymerization of Meso-epoxides and Cyclic Anhydrides: Efficient Access to Enantiopure Polyesters. J. Am. Chem. Soc. 2016, 138, 11493-11496.

21. Bernard, A.; Chatterjee, C.; Chisholm, M.H. The influence of the metal (Al, $\mathrm{Cr}$ and $\mathrm{Co}$ ) and the substituents of the porphyrin in controlling the reactions involved in the copolymerization of propylene oxide and cyclic anhydrides by porphyrin metal(III) complexes. Polymer 2013, 54, 2639-2646. [CrossRef]

22. Liu, Y.; Guo, J.-Z.; Lu, H.W.; Wang, H.B.; Lu, X.B. Making Various Degradable Polymers from Epoxides Using a Versatile Dinuclear Chromium Catalyst. Macromolecules 2018, 51, 771-778. [CrossRef]

23. Robert, C.; De Montigny, F.; Thomas, C.M. Tandem synthesis of alternating polyesters from renewable resources. Nat. Commun. 2011, 2, 586. [CrossRef] [PubMed]

24. Poland, R.R.; Escobedo, C.; Darensbourg, D.J. Kinetic Studies of the Alternating Copolymerization of Cyclic Acid Anhydrides and Epoxides, and the Terpolymerization of Cyclic Acid Anhydrides, Epoxides, and $\mathrm{CO}_{2}$ Catalyzed by (salen)Cr III Cl. Macromolecules 2012, 45, 2242-2248.

25. Bao, Y.Y.; Liu, Y.; Ren, W.M.; Lu, X.B.; Liu, J. Binuclear chromium-salan complex catalyzed alternating copolymerization of epoxides and cyclic anhydrides. Polym. Chem. 2013, 4, 1439-1444.

26. Huijser, S.; Hosseininejad, E.; Sablong, R.; De Jong, C.; Koning, C.E.; Duchateau, R. Ring-Opening Co- and Terpolymerization of an Alicyclic Oxirane with Carboxylic Acid Anhydrides and $\mathrm{CO}_{2}$ in the Presence of Chromium Porphyrinato and Salen Catalysts. Macromolecules 2011, 44, 1132-1139. [CrossRef]

27. Liu, D.F.; Zhu, L.Q.; Wu, J.; Wu, L.Y.; Lü, X.Q. Ring-opening copolymerization of epoxides and anhydrides using manganese( III ) asymmetrical Schiff base complexes as catalysts. RSC Adv. 2015, 5, 3854-3859. [CrossRef]

28. Robert, C.; Ohkawara, T.; Nozaki, K. Manganese-Corrole Complexes as Versatile Catalysts for the Ring-Opening Homo- and Co-Polymerization of Epoxide. Chem. Eur. J. 2014, 20, 4789-4795. [CrossRef] [PubMed]

29. Mundil, R.; Hošt'álek, Z.; Šeděnková, I.; Merna, J. Alternating ring-opening copolymerization of cyclohexene oxide with phthalic anhydride catalyzed by iron(III) salen complexes. Macromol. Res. 2015, 23, 161-166. [CrossRef]

30. Garden, J.A.; Saini, P.K.; Williams, C.K. Greater than the Sum of Its Parts: A Heterodinuclear Polymerization Catalyst. J. Am. Chem. Soc. 2015, 137, 15078-15081. [CrossRef]

31. Zhu, Y.; Romain, C.; Williams, C.K. Selective Polymerization Catalysis: Controlling the Metal Chain End Group to Prepare Block Copolyesters. J. Am. Chem. Soc. 2015, 137, 12179-12182. [CrossRef]

32. Thevenon, A.; Garden, J.A.; White, A.J.P.; Williams, C.K. Dinuclear Zinc Salen Catalysts for the Ring Opening Copolymerization of Epoxides and Carbon Dioxide or Anhydrides. Inorg. Chem. 2015, 54, 11906-11915. [CrossRef] [PubMed] 
33. Yu, C.Y.; Chuang, H.J.; Ko, B.T. Bimetallic bis(benzotriazole iminophenolate) cobalt, nickel and zinc complexes as versatile catalysts for coupling of carbon dioxide with epoxides and copolymerization of phthalic anhydride with cyclohexene oxide. Catal. Sci. Technol. 2016, 6, 1779-1791. [CrossRef]

34. Nejad, E.H.; Van Melis, C.G.W.; Vermeer, T.J.; Koning, C.E.; Duchateau, R. Alternating Ring-Opening Polymerization of Cyclohexene Oxide and Anhydrides: Effect of Catalyst, Cocatalyst, and Anhydride Structure. Macromolecules 2012, 45, 1770-1776. [CrossRef]

35. Hošt'álek, Z.; Trhlíková, O.; Walterová, Z.; Martinez, T.; Peruch, F.; Cramail, H.; Merna, J. Alternating copolymerization of epoxides with anhydrides initiated by organic bases. Eur. Polym. J. 2017, 88, 433-447. [CrossRef]

36. Kummari, A.; Pappuru, S.; Chakraborty, D.; Kanji, A. Fully alternating and regioselective ring-opening copolymerization of phthalic anhydride with epoxides using highly active metal-free Lewis pairs as a catalyst. Polym. Chem. 2018, 9, 4052-4062. [CrossRef]

37. Shi, Z.; Jiang, Q.; Song, Z.; Wang, Z.; Gao, C. Dinuclear iron(iii) complexes bearing phenylene-bridged bis(amino triphenolate) ligands as catalysts for the copolymerization of cyclohexene oxide with carbon dioxide or phthalic anhydride. Polym. Chem. 2018, 9, 4733-4743. [CrossRef]

38. Darensbourg, D.J. Making Plastics from Carbon Dioxide: Salen Metal Complexes as Catalysts for the Production of Polycarbonates from Epoxides and $\mathrm{CO}_{2}$. Chem. Rev. 2007, 107, 2388-2410. [CrossRef]

39. Darensbourg, D.J.; Ulusoy, M.; Karroonnirum, O.; Poland, R.R.; Reibenspies, J.H.; Çetinkaya, B. Highly Selective and Reactive (salan) $\mathrm{CrCl}$ Catalyst for the Copolymerization and Block Copolymerization of Epoxides with Carbon Dioxide. Macromolecules 2009, 42, 6992-6998. [CrossRef]

40. Fieser, M.E.; Sanford, M.J.; Mitchell, L.A.; Dunbar, C.R.; Mandal, M.; Van Zee, N.J.; Urness, D.M.; Cramer, C.J.; Coates, G.W.; Tolman, W.B. Mechanistic Insights into the Alternating Copolymerization of Epoxides and Cyclic Anhydrides Using a (Salph)AICI and Iminium Salt Catalytic System. J. Am. Chem. Soc. 2017, 139, 15222-15231. [CrossRef] [PubMed]

41. Van Zee, N.J.; Coates, G.W. Alternating Copolymerization of Propylene Oxide with Biorenewable Terpene-Based Cyclic Anhydrides: A Sustainable Route to Aliphatic Polyesters with High Glass Transition Temperatures. Angew. Chem. Int. Ed. 2015, 54, 2665-2668. [CrossRef] [PubMed] 